\title{
(In)Visible Bleeding: The Menstrual Concealment Imperative
}

\author{
Jill M. Wood
}

Researchers and scholars from various and diverse backgrounds have long discussed the degree to which society views women's menstruation ${ }^{1}$ as taboo, shameful, disgusting, and consequently is shrouded in secrecy (for example, Bobel 2006; Brooks-Gunn and Ruble 1982; Golub 1992; Johnston-Robledo et al. 2003; Stubbs and Costos 2004; Ussher 1989). Menstrual taboos that stigmatize women still abound in the US, serving to limit women's ability to fully participate in their lives and in society (for example, Johnston-Robledo and Chrisler 2013; Patterson 2014; Ussher 1989, 2006). Houppert (1999) coined the phrase "the culture of concealment" to explain how menstrual taboos and stigma shape women's experience of menstruation and manipulate women into menstrual shame and secrecy, often via menstrual hygiene products. Similarly, the commodification of menstruation through "feminine hygiene" care continues to promise new and improved ways for women to keep themselves "clean" and their periods a secret-either by opting out of menses altogether via menstrual suppression or through products that render menses invisible.

Simultaneously, the medicalization of menstruation conceptualizes women as deficient, ill, and diseased, and menses in need of medical treatment and management (for example, Lippman 2004; Wood et al. 2007). Through medicalization, menstruation is constructed as a "health" issue from a biomedical perspective and jurisdiction for how to treat and monitor it is assigned to the medical system. This conflation of biology as ideology serves to limit women's participation both in their private and public lives because menses marks women not only as physically ill but also as emotionally impaired. In this way, medical social control results through ideological frameworks that define and discipline menstruation as a health issue. 
The conceptualization of menstruation as disease and the association of menstruation with femaleness has established menstruation as a political issue (for example, Bobel 2010; Ussher 2006).

While Houppert has described the significance of the culture of concealment surrounding menstruation, this chapter explains menstrual concealment an as imperative that women adopt through their internalization of and adherence to menstrual discourse. "The menstrual concealment imperative" is a conceptual framework to explain how women's internalized perceptions of menstruation as diseased, taboo, and stigmatized contribute to their disembodiment and self-objectification (Roberts 2004). It suggests that women's vigilance about menstrual concealment is a form of self-surveillance and self-objectification that is fostered by the medicalization of women's bodies and neoliberal approaches to women's health. The potential for menstruation to be oppressive is rooted in a complex, multifaceted, and all-encompassing imperative for women that functions as gendered body politics to (re)produce the very conceptualization of women's bodies as othered (de Beauvoir 1952). Offering a critique of the medical system and menstrual hygiene industry, this paper analyzes menstrual discourse that establishes women as diseased and as unable to know their bodies. Using a neoliberal rhetoric of "choice" the menstrual hygiene industry cleverly posits menstrual concealment as "freedom" and thereby facilitates women's complicity in their own subjugation. I offer "the menstrual concealment imperative" as a theory to explain how women's internalization of the culture of concealment is form of social control and a body project (Brumberg 1998) that keeps women disembodied and oppressed.

\section{Menstrual Discourse}

In this section, I use Foucault's work on discourse to explain the significance of the production of menstrual knowledge as oppressive to women. First, I will discuss Foucault's conceptualization of discourse and biopower as it relates to menstrual discourse. Next, I will discuss the significance of menstrual taboos and menstrual stigma. Finally, I will discuss medicalization in terms of how menstrual discourse constructs women as diseased by virtue of their menses, and therefore how knowledge production by the medical field and the associated female hygiene industry establishes women as perpetually disempowered.

Foucault's (1984) concept of biopower explains how social norms and expectations embedded in microlevels of everyday life coalesce into powerful discourses that shape what is considered normal on both individual and societal levels. Arguing that biopower is produced through discourse (and individuals' desire to adhere to it), he explains how pressure to conform to cultural norms produces individuals' voluntary self-subjugation. In this way, biopower is a form of social control enacted through individuals' internalization of dominant discourses that result in self-disciplinary practices. Foucault argues that biopower is especially salient in terms of regulating bodies 
through medicine and technology because of discourse structures social and individual attitudes, thoughts, and behaviors as if the knowledge is objective. However, this knowledge is characterized by a specific epistemological stance in order to maintain ideological control. Ussher (2006) argues that biopower constructs the female body as deviant, polluted, and "monstrous" based on reproductive processes like menstruation, regulating women's bodies through discourse that positions it as in need of surveillance and treatment. Menstrual discourse constructs women's bodies as diseased, shameful, and polluted. Foucault's concept of biopower elucidates how women's bodies are a site of self-discipline and how these practices produce 'docile bodies' (for example, Bartky 2014; Bordo 1989; Pylpa 1998; Patterson 2014). Pylpa explains: “... medicine creates the discourse that defines which bodies, activities, and behaviors are normal; at the level of practice, medical procedures are a principal source of the institutional regulation and disciplining of bodies" (30). In this way, menstrual discourse creates biopower at both micro and macro levels. Individuals voluntarily conform to disciplinary strategies of their bodies through their own desire (Foucault 1977), and in doing so biopower is produced and (re)produced. Foucault's work prompts an analysis of menstrual discourse that asks questions about how menstrual knowledge is produced and by whom, what constitutes knowing about menses, and who has authority and power to produce menstrual knowledge. Later in this chapter, I will use feminist analyses of Foucault's work on biopower to argue that women's internalization of menstrual discourse results in their self-surveillance of their menstruation and ultimately explains women's internalized need for menstrual concealment.

\section{Menstrual Taboos, Stigma, and Silence}

The prominence and significance of menstrual taboos and stigma in women's lives has been well documented by scholars in various disciplines for decades (for example, Bobel 2006; Brooks-Gunn and Ruble 1982; Buckley and Gottlieb 1988; Golub 1992; Roberts 2004; Stubbs and Costos 2004; Ussher 1989). Evidence of how menstrual taboos stigmatize women is evidenced in the description of how menstruation and menstrual blood have been variously described, as: simultaneously magical and poisonous (Golub 1992); an abomination (Rozin and Fallon 1987), disgusting and aversive (Bramwell 2001), contaminating (Laws 1990) unclean and unpure (Cicurel 2000), a threat to femininity (Lee 1994), and a blemish to a one's character (Johnston-Robledo and Chrisler 2013). Menstruating women are also perceived as a danger to men and a threat to male power (Delaney et al. 1988; Guterman et al. 2007).

The consequence of menstrual taboos for women's lives is significant and varied as prohibited behavior for menstruating women is contextualized culturally, geographically, and according to religious and other social practices. Many women report their need to maintain cleanliness during menses, 
and most women report altering their usual activities during menses (Jurgens and Powers 1991). Indeed, women's motivation to change their behavior during their menses may be a reasonable precaution as menstruating women are harshly judged and characterized as irritable and unsexy (Forbes et al. 2003). Roberts et al. (2002) found that by virtue of simply having a tampon visible in her bag, a woman is perceived as less likeable, less competent and that observers made an effort to physically distance themselves from her. Menstrual taboos function to separate, exclude, and even banish menstruating women from public and private spheres preventing their full participation in public life as well as in their own full subjectivity (for example, Johnston-Robledo and Chrisler 2013; Roberts 2004; Thomas 2007; Thornton 2013; Ussher 2006).

Silence perpetuates menstrual stigma and is a key indicator of the culture of concealment (Delaney et al. 1988; Houppert 1999; Kissling 2006). Menstruation is considered inappropriate public conversation to the extent that girls and women are often too uncomfortable to discuss the topic even with each other, healthcare providers, or family members (for example, Golub 1992; Houppert 1999; Johnston-Robledo and Chrisler 2013). Ussher (2006) describes women's "unspeakable bodies" referring to how the silence surrounding menstrual shame results in women's self-isolation. Similarly, Houppert's (1999) "culture of concealment" explains how sociocultural influences construct menstruation not just as taboo, shameful, and debilitating but also as invisible in US culture. She details the powerful influence that the menstrual product industry has to conceptualize menstruation as an illness, and how the development and advertisement of menstrual products create and reinforce women's insecurities around their periods as a hygiene crisis. In this way, menstrual product companies convince women to conceal their periods, and then provide their own products to enable that concealment, reinforcing cultural attitudes that menstruation is embarrassing and should be kept secret. Menstrual discourse disempowers women by not only constituting menstruation as a negative, taboo, and stigmatized event that women must conceal, but also by enabling others to produce knowledge about women's bodies that is not based on their own situated knowledge and experiences.

\section{The Medicalization of Women's Bodies}

In addition to the conceptualization of menstruation as taboo and stigmatized, menstrual discourse is also characterized by the medicalization of menstruation that further constructs menstruation as a disease process in need concealment via medical management. Conrad (1992) explains medicalization as a sociocultural process that functions as a form of social control. Women are especially vulnerable to medicalization and an overwhelming majority of women's natural life processes have been medicalized 
(Conrad 1992; Ehrenreich and English 2005). As such, feminist researchers and women's health activists critique the over-medicalization of normal, natural, healthy body processes that characterize women's everyday lives (for example, Kaufert and Gilbert 1986; Lippman 2004; Tiefer 1995). These scholars have demonstrated how women's bodies, especially reproductive processes, are medicalized as a form of political and social control to the detriment of women's health and lives (for example, Ussher 2006; Ruzek 1978; Wood et al. 2007).

The medicalization of women's bodies has significant consequences for women's lives. First, women are ideologically constructed as deficient, ill, and diseased to legitimate the need for medical treatment and constant medical surveillance. Secondly, medicalization functions as a form of social control by establishing medical practitioners as the experts on women's bodies based on women's illness as defined by the medical model. Kaufert and Gilbert (1986) argue that when women are not considered capable of knowing their bodies then their subjective experience of themselves shifts to that of a patient. As patients, women are morally obligated to be treated and medical practitioners are ethically required to diagnose and treat their assumed diseased state. In this way, the medicalization of menstruation contributes to menstrual discourse that positions women in a constant state of disease. As Ehrenreich and English (2005) explain, "Not only [are] women seen as sickly - sickness [is] seen as feminine" (22).

While scholarship on medicalization as a theoretical framework has existed for decades, biomedicalization has been more recently described as distinct from medicalization both in terms of historical context and an increased focus on techno-scientific processes (Clarke et al. 2010). Like medicalization, the biomedicalization of menstruation shapes menstrual discourse through the production of knowledge that establishes women as unable to know their own bodies. While medicalization controls bodies through defining disease, biomedicalization encourages the transformation of bodies based on the construct of health, so that biomedicalization is broader, more invasive, and reaches into lifestyle decisions around health, risk, illness, and wellness as a moral imperative. The biomedicalization of health is characterized by a more complex and insidious structure of knowledge production and dissemination, including the corporatization of medicine. No longer is medical discourse produced solely by medical experts, but also by pharmaceutical companies, media outlets, alternative medicine practitioners, patient self-help groups, and research conglomerates that often advertise products, drugs, technologies, and information targeted directly to consumers. In biomedicalization, it is not an illness, disease, or, dysfunction that is treated as in medicalization, but the risk of these (Armstrong 1995). Because "health" is so broadly conceptualized, so poorly defined by so many "health experts," and health recommendations constantly change, individuals no longer need to be sick to be treated; simply the risk of eventual poor health is sufficient for intervention. When 
health is no longer conceptualized as the absence of disease, the possibilities for diagnosis, treatment, and intervention to address the risk of illness is literally endless (Clarke et al. 2010).

Despite theoretical distinctions between medicalization and biomedicalization, I use the term (bio)medicalization in this chapter to refer to the simultaneous ways that women's menstrual bodies are transformed, regulated, and controlled through menstrual discourse. Because menstruation is conceptualized from a biomedical perspective as a form of illness, women are encouraged to transform their bodies to prevent potential hazards of menstruation. Technological and pharmaceutical interventions promise menstrual concealment to women as an individual "choice" (for example, menstrual suppression) by transforming women's menstrual bodies into non-bleeding ones. Similarly, menstrual products are marketed to women as hygiene products so that women can manage (conceal) their menses as part of their individual responsibility for their own health. In this way, (bio)medicalization contributes to menstrual discourse by establishing the amorphous healthcare industry as the experts on menstruation while assigning women to the perpetual role of patient. Together, the (bio)medicalization of menstruation and menstrual stigmas and taboos function to create a menstrual discourse which controls women's bodies and lives based on epistemologically flawed biomedical ideologies. Menstrual concealment is constituted in menstrual discourse as an individual women's "choice" as part of her own pursuit of her health. In order to understand how the menstrual concealment becomes an imperative for individual women, next I will consider how women internalize menstrual discourse through self-surveillance.

\section{Self-Surveillance and Self-Objectification}

In this section, I explain how menstrual discourse and biopower facilitate women's internalization of menstrual self-surveillance as imperative menstrual concealment practices. According to Foucault (1977), individuals come to desire conformity to discourse through biopower and engage in a resultant process of self-surveillance through panoptical power. The panopticon is a paragon of how to socialize masses into a state of constant self-policing so that individuals conform to "normal" behaviors and attitudes without the need for external enforcement. Through discourse, these norms become so desirable for individuals to obey that they then voluntarily self-monitor their adherence to them. Knowledge produces discourse that establishes cultural norms that individuals desire to conform to; because the knowledge is presented as objective and "true," individuals organize their behavior around the discourse, thereby enacting their own practice of self-surveillance and self-discipline. This constant self-surveillance and self-regulation is posited as individualism, despite the fact that it is culturally created, and in this way biopower is difficult to see as external to the individual (Bartky 2014; Foucault 1977). 
Bartky (2014) builds on Foucault's work, noting how gendered notions of power in self-surveillance practices are especially problematic for women and their bodies. She argues that the panoptical gaze is male, and therefore that women's self-surveillance based on this patriarchal view results in their disembodiment. Barkty discusses her work in the context of women's self-monitoring of their own appearance, explaining that women internalize and embody patriarchal notions of beauty and subsequently adopt body projects (Brumberg 1998) to change their bodies to adhere to cultural beauty norms. Women readily enact these body projects as part of their own self-surveillance and self-disciplinary practices resulting in the production of their own docile bodies. Women's discipline of their own bodies via an internalized patriarchal panoptical view is insidious because the authority to maintain control of women's bodies is both nowhere and everywhere, and it is neither natural nor completely voluntary. That is, when women practice self-disciplining body projects they do so without coercion but not by their own free will either.

Just as Bartky uses Foucault's work on biopower, discourse, and self-surveillance to analyze women's self-subjugation around appearance, this chapter applies those concepts to menstruation. Menstrual discourse is characterized by negative views of menstruation that encourage girls and women to self-surveil and manage their bodies to maintain menstrual secrecy (for example, Chrisler 2004; Erchull et al. 2002; Martin 1992; Stubbs and Costos 2004). Whether learned through mothers, educators, product advertisements, or other girls, menstrual discourse encourages girls and women to perceive their bodies as polluted and shameful, and as such, out of their control (Chrisler 2004; Jackson and Falmagne 2013). Ussher (2006) argues that when menstruation is positioned as a form of embodied pathology menstrual discourse encourages women's self-surveillance, self-policing, self-silencing, self-blame, self-sacrifice, and contributes to women's guilt, shame, and blaming of the body.

Other feminist scholars have also established that women's bodies are sites of discipline and that subjectivity is tied to the body, which is constantly in need of management, containment, and discipline (for example, Bartky 2014; Bordo 1990; Lee 1994; Martin 1992; Young 1997). Moreover, because women are primarily valued based on their appearance, self-disciplinary body projects (Brumberg 1998) are strongly associated with femininity. Such body projects reify patriarchal constructs of femininity as women judge themselves as "good" or "bad" women based on how well they conform to standards of femininity that require them to distance their bodies from their selves (Roberts and Waters 2004). In order to be "good," women are necessarily disembodied, objectified, and self-silenced from their menstrual bodies (Roberts and Waters 2004; Ussher 2006). Ussher argues that menstrual discourse posits women as closer to nature due to their bodily subjectivity, and in this way women's reproductive bodies are a marker of "hegemonic constructions of femininity" (2). As such, menstrual discourse constructs 
women's bodies as pathological and defines women based on their reproductive capacity, associating femininity with women's ability to maintain the secrecy of their polluted bodies. Ussher explains that the implications of defining women as a held hostage by their menstrual bodies are significant in how women can inhabit and know their own bodies as well as the development of women's subjectivity.

Similarly, Persdotter (2020, this volume) introduces the concept of menstronormativity to expand menstrual discourse as a more all-encompassing process and system that describes the ordering of menstruation on both sociocultural levels and in individual's lives. Menstronormativity, the aggregate of menstrual norms, stigmas, etiquette, and discourse, describes the regulation of some menstrual subjectivities as "good" and others as "bad." Women's acceptance of menstronormativity fuels self-surveillance and self-disciplinary body projects. The process through which women adopt this internalized male gaze of their bodies and selves can be understood through objectification theory and ultimately, women's self-objectification.

Objectification theory explains how the sexual objectification of girls and women functions to separate their bodies from their personhood so that female bodies are viewed in terms of how they serve others, often the sexual interests of men (Bartky 1990; Fredrickson and Roberts 1997). When women internalize this objectification, they adopt an outsider's view of themselves, evaluating their bodies and appearance from a sexually objectified gaze; this is the process of self-objectification (Fredrickson and Roberts 1997). Fredrickson and Roberts argue that self-objectification explains a woman's sense of self-detachment from her own body. As such, self-objectification is one-way women unwittingly participate in their own oppression.

Self-objectification is a common practice for women, especially around reproductive functions like menstruation, and it is associated with a host of negative health effects including increased body self-surveillance, body shame, and negative attitudes about body functions like menstruation (Johnston-Robledo et al. 2003; Roberts and Waters 2004; Roberts 2004). Roberts (2004) applies objectification theory to menstruation, arguing that as women internalize US culture's sexual objectification of themselves that menstruation must be concealed in order to appear as adequately feminine, attractive, and sexually desirable. Women who engage in self-objectifying menstrual practices also report more self-surveillance and associated feelings of shame, self-loathing, and self-disgust. In this way, self-objectification prevents women from inhabiting their bodies in an emotionally and physically authentic way. This contributes to women's alienation from their subjective experiences and is a form of de-selfing as women replace their own sense of self with an outsider's (male) gaze (Roberts and Waters 2004, 13).

Because menstruation is viewed as the antithesis of a sexually desirable feminine body, women learn that to be sexually desirable, attractive, and feminine menstruation must be concealed (Grose and Grabe 2014). For instance, Erchull's research found that women's bodies are portrayed as 
highly sexualized even in ads for menstrual products, illustrating the need for women to use such products for menstrual concealment in order to ensure their constant sexually availability. Other researchers have also found that women's attitudes toward their menstrual bodies are incompatible with their internalized valuing of their bodies as sexually desirable (Johnston-Robledo et al. 2007). In this way, women's self-objectification contributes to their desire to distance themselves from their bodies via menstrual concealment (Erchull 2013; Grose and Grabe 2014; Roberts 2004; Roberts et al. 2002) or menstrual suppression (Johnston-Robledo et al. 2007).

As problematic as self-objectification and its associated risks are for women, adherence to idealized female body standards may be logistically beneficial to women in a patriarchal culture. For example, Fredrickson and Roberts (1997) propose that self-objectification might appear to women as a strategy to claim power in a patriarchal system in which attractiveness is currency. Just as women benefit economically from being attractive, women who distance themselves from their bodies, especially menstruating bodies that are feared and abhorred, have more opportunities in the public sphere (Roberts and Waters 2004). In this way, menstrual concealment serves as a tool to distance oneself from the feminine, and it does benefit women in terms of their acceptance in a patriarchal society. In this way self-objectification can be considered a survival strategy to present their bodies in an idealized form, and in this way self-objectification is about self-surveillance (Roberts and Waters 2004).

\section{The Menstrual Concealment Imperative}

As women self-objectify through a patriarchal body-hating view of themselves, menstrual concealment offers women a way to "free" themselves from their monstrous body. Women not only feel obligated to render their periods invisible, but when framed as an empowering choice, menstrual concealment falsely offers women a sense of control over their out of control bodies. As a theory, the "menstrual concealment imperative" explains how women internalize menstrual discourse and willingly practice self-surveillance and self-disciplining body projects, even though such practices are self-subjugating and disempowering. This section of the chapter will explain menstrual concealment as a required form of self-surveillance in which women become disembodied through this self-disciplinary practice in their search for "freedom" from and control over their bodies.

The menstrual concealment imperative is about freedom and control to women; "freedom" from their bodies that mark them as othered and are a significant source of their oppression. The concealment imperative offers a solution to women's objectified, pathologized, and then self-objectified bodies, yet women become disembodied through these self-disciplinary concealment practices. In this way, the concealment imperative is a panopticon-like form of social control that women willingly participate in, and as they do so 
women become complicit in a menstrual discourse that requires them to be disembodied and objectified. When women internalize these negative perspectives via self-objectification, menstrual concealment is no longer a cultural norm but a moral imperative to exist in a patriarchal society. Without agency to contextualize their own menstrual experiences, women desire distance from their menstrual bodies and menstrual concealment offers this disembodiment. The menstrual concealment imperative is a self-perpetuating cycle of self-surveillance, self-discipline, and self-subjugation.

Menstrual concealment is imperative for menstruating women for several reasons. First, menstrual concealment is required for women to be considered as competent (Roberts et al. 2002), attractive and sexually appealing (Erchull 2013). In order to succeed in public life women must transform their bodies to meet patriarchal expectations for how their bodies appear to others and how their bodies impact others' feelings about them in terms of comfort, sexual attractiveness, and hygiene. Menstrual concealment benefits women socially, politically, and personally because menstruation marks bodies as feminine and therefore as weak. Practically speaking, women are more successful in their lives if they appear unencumbered by their menses. The menstrual concealment imperative explains practical benefits in women's public and private lives that may result from their concealment practices.

Secondly, women perceive menstrual concealment as imperative because menstrual discourse dictates how women experience their menstruation as polluted, unclean, disgusting, and as an illness to be managed. Menstrual discourse conceptualizes menstruation as pathological and posits the transformation of the diseased body as the "right" way to avoid possible risks associated with menstruation. In (bio)medicalization terms, menstrual concealment is both control over and transformation of the female body into one that is less stigmatized. Surveillance medicine requires the management of the menstrual body through menstrual concealment as a moral obligation for women as patients and health care consumers to avoid ambiguous risks associated with the illness of menstruation. Menstrual concealment is imperative for women to avoid illness and consider themselves "healthy." Moreover, women may feel out of control in their bodies when their bodies are positioned as monstrous, disgusting, and diseased; menstrual products are offered as a way for women to "control" their bodies. As such, menstrual products are a technology used to transform the dysfunction of the menstruating female body into a non-menstruating one (Vostrel 2008). Thus, the menstrual concealment imperative is constructed and (re)produced through menstrual discourse and menstronormativity to allow women to dissociate from their bodies that mark them in oppressive ways. Because stigma surrounding the menstrual body threatens women's full access to the public sphere (Thomas 2007), it is understandable that women willingly become disembodied as a potentially liberating tactic in patriarchal culture.

Finally, menstrual concealment is imperative because in women's private lives it marks them as "good women." Patriarchal standards of femininity are 
rooted in how women's bodies serve others; women's bodies must be clean, sexually attractive, and not inconvenient or uncomfortable for others. Girls adopt the concealment imperative very early; at menarche, they learn how to manage their menstrual shame by the concealment of their menstruation in order to prevent others' discomfort (Kissling 1996; Jackson and Falmagne 2013). Through self-objectification of themselves as monstrous, girls and women adopt self-surveillance and self-disciplinary practices to conceal their menses. Thus, menstrual concealment is imperative for women to consider themselves "good" based on patriarchal standards of femininity that require women's docile bodies; there is little possibility for women to avoid menstrual concealment and still claim an identity as "a good woman," "healthy," "attractive," or even "smart." When women self-objectify and internalize hegemonic requirements for their bodies based on patriarchal standards of femininity, women must necessarily become disembodied or risk self-hatred (Roberts 2004). That is, the inability for women to avoid self-hatred without menstrual concealment illustrates the imperative nature of menstrual concealment.

Women may interpret menstrual management and concealment as a form of empowerment and control over their bodies, especially when menstrual concealment is marketed to women as convenience that is characterized as "freedom." The menstrual product industry has created a market for their own products based on the culture of concealment (Houppert 1999), referring to these products, as "feminine hygiene" and "sanitary protection" to reinforce the notion that menstruation is an unsanitary condition that girls and women need to protect themselves and others from (Vostrel 2008). Menstrual product advertising and direct to consumer (product) education reinforces (bio)medicalization and reifies women's need to conceal their menstruation. Products are marketed to girls and women as convenience and "freedom" from their bodies because of how effective they are at enabling women to conceal their menstruation. For instance, Proctor and Gamble advertise "Always My Fit" to women as their allies in "better period protection" through a custom fit sizing chart, now available on the top of all pad packages. The brand claims that, " $60 \%$ of women wear the wrong size pad and $100 \%$ can change that!" (always.com 2017, "Tips and Advice Choosing a Pad"). Using a neoliberal approach to target women's self-loathing of their menstrual bodies, Always My Fit offers pseudo control, choices, and power to women, “... when many women experience a leak they often blame themselves ... the truth is that a lot of women do not know that leak free periods are possible [if you find] the right pad coverage."

For these reasons, menstrual concealment may feel empowering to women, especially as the commodification of menstruation offers women the ability to purchase freedom from their bodies through menstrual products that claim to be specially designed for them. The pressure for body transformation, like menstrual concealment, as a form of individualism and "choice" is characteristic of (bio)medicalization, panoptical forms of social control, 
and neoliberalism. As such, it is hard to identify as imperative. Bartky (2014) argues that the lack of an enforcer in the disciplining of female docile bodies makes women's subordination seem isolated, normal, and appears as more of an individual choice than an institutional mandate. In this way, the menstrual concealment imperative is both invisible and self-sustaining.

Yet, because menstrual concealment is imperative for women's acceptance and success in both their public and private lives, this practice of self-discipline is not a true choice. I argue that women "choose" to become disembodied and self-subjugating as a form of false consciousness due in part to the conceptualization of concealment as a cultural norm instead of as an imperative. Reframing menstrual concealment practices as imperative self-disciplining behaviors offer a framework to understand women's "choice" to conceal menstruation as a false one for several reasons. First, the risk for women not to conceal is tremendous including being judged as incompetent, emotional, unattractive, unclean, and diseased. Women may prudently judge that given other forms of gender oppression, menstrual concealment benefits them in important logistical ways like obtaining or maintaining employment and/or long-term partnerships or marriage. For example, Bartky (2014) discusses that women risk the refusal of male patronage and related intimacy as well as success in their economic and social livelihood when they avoid forms of bodily self-discipline. Moreover, a woman's sense of herself will likely be compromised by avoiding self-disciplinary practices because they are so critical to social constructions of herself as a woman and individual (Bartky 2014). Secondly, women are often not aware that menstrual concealment is a self-disciplinary practice as a result of their own self-objectification of their bodies. When menstrual concealment is marketed to women as convenience or empowerment, the imperative nature of concealment is rendered invisible. Third, women cannot make a true choice about their menstruation when they are distanced from their bodies. Without agency and subjectivity, women's ability to make decisions, as is characteristic of true choice, is impossible. Fahs (2014) distinguishes between the 'freedom to' and the 'freedom from' in regard to women's subjectivity and agency, arguing that a feminist understanding of freedom must involve both aspects of freedom. In this way, women's freedom to choose menstrual concealment is dependent on women's freedom from menstrual stigmas that mandate menstrual concealment. Finally, menstrual concealment cannot be a true choice for women when alternatives to it are not presented. For menstrual concealment to be a viable choice, women must be able to choose to claim their menstrual realities just as freely as they opt to conceal menses.

\section{The Future}

Feminist menstrual researchers have remarked on "unspeakable womanhood" (Ussher 2017) and a missing discourse around women's reproductive bodies (Roberts 2017). I offer the menstrual concealment imperative as a 
conceptual tool for menstrual scholars and researchers to refer to the totality of the various interrelated processes and layered structural barriers that contribute to women's oppression via menstrual discourse. The invisibility of the menstrual concealment imperative contributes to how insidious it is in women's lives; when women internalize menstrual discourse they become disembodied, self-objectify and willingly engage in their own self-surveillance and self-discipline. One possible implication of the menstrual concealment imperative as a theoretical tool is that by describing and naming it, then the imperative for women to conceal their menstruation is visible and less insidious. This visibility lends legitimacy to women's experiences and therefore creates the possibility for resistance to menstrual concealment as imperative for women's freedom and success in the private and public spheres. Resistance to the menstrual concealment imperative must begin with making it visible, as Ussher explains: "Identifying self-policing practices allows women to develop more empowering strategies for reducing or preventing ... distress, developing an ethic of care for the self, and no longer blaming the body ..." (2).

Notably, women's voices and experiences are largely missing from menstrual discourse because of their disembodiment, and therefore women's own voices and positive experiences of menstruation can be seen as a form of resistance. Patterson (2014) argues that resistance to normative menstrual discourse can range from being "period positive" to more radical forms of menstrual activism, as is characteristic of menarchists: "Menarchists argue that women need to take back the power of their bodies by publicly undermining patriarchal attempts at control that lead to women's bodily self-loathing. They call on women to reclaim their bleeding bodies, and the entitlement to bleed without secrecy and shame" (105-6). Bobel (2010) explains how menstrual activists, acting in their individual lives, can create change at level of menstrual discourse: "The activists subvert the precepts of the dominant narrative of menstruation and strive for an authentic autonomous embodiment. Their aim is to seize agentic menstrual consciousness from the docile, disciplined body and stimulate new ways of knowing and being that neither shame nor silence" (41).

Yet, to resist the menstrual concealment imperative on an individual level, a woman has to resist the internalization of her objectified menstrual body and resulting self-discipline in the form of "menstrual management." Thus, I argue that menstrual management of any kind, even with environmentally conscious do-it-yourself, reusable products, is a defining characteristic of the menstrual concealment imperative because "management" is a form of concealment. As Persdotter (2020, this volume) argues with her concept of menstronormativity, we exist in and simultaneously produce menstrual norms so that it is hard to operate outside the boundaries of this power. Foucault also struggled with the possibility of how to transgress the power of discourse while inside discourse; one possibility for imagining resistance to the menstrual concealment imperative is via his work on resistance as counter-power (Pickett 1996). Free bleeding, or the refusal to use products to collect 
menstrual blood, is one possible form of women's resistance to the menstrual concealment imperative. In fact, free bleeding as a movement is a form of collective unity and activism among menstruators against menstrual stigma, shame, and the culture of concealment that fuels the need for menstrual management and menstrual "hygiene" products that are increasingly commodified in capitalist cultures (for example, Bobel 2006; Fahs 2016; Lapekas 2013).

In conclusion, in order to resist the concealment imperative at the level of discourse, we must be able to locate it as just one possibility of relating to our menstrual bodies; in order to contest menstrual concealment as imperative, we must locate the imperative as a false truth that appears as all-encompassing because it serves to keep women simultaneously tied to and alienated from their bodies as part of what it means to be "good." The menstrual concealment imperative is a body project (Brumberg 1998) that keeps women in a psychological state of self-hatred and constantly preoccupied with their physical bodies as a way to keep women busy and "in their place." After all, the menstrual concealment imperative is rooted in menstrual taboos and stigmas based on men's fear of women's menstruation (Delaney et al. 1988; Guterman et al. 2007) and women's own self-internalized fear of their menstrual bodies. The menstrual concealment imperative has implications to understand the various ways in which women's bodies are regulated at sociocultural and individual levels. As women's ability to control their own bodies is increasingly under political attack, it is critical to illuminate the ways in which women's disembodiment and willingness to distance themselves from their authentic experiences feeds patriarchal control of women's bodies and therefore their lives. If menstrual concealment can be disentangled from menstrual discourse that dictates self-surveillance and self-objectification of women's self-shamed bleeding bodies, the possibility exists for women to navigate their menstrual experiences with embodied subjectivity.

\section{Note}

1. I acknowledge the inherent risks associated with essentializing 'women' as menstruators, and yet the feminization of women's reproductive bodies as polluted and diseased contributes to menstrual concealment as imperative for female bodies. See Bobel $(2010,11-13)$ for a discussion of the gendered language around menstruators.

\section{REFERENCES}

Armstrong, David. 1995. "The Rise of Surveillance Medicine." Sociology of Health and Illness 17 (3): 393-404.

Bartky, Sandra Lee. 1990. Femininity and Domination: Studies in the Phenomenology of Oppression. New York: Routledge.

. 2014. "Foucault, Femininity, and the Modernization of Patriarchal Power." In The Politics of Women's Bodies: Sexuality, Appearance, and Behavior, 4th ed., edited by Ruth Weitz and Kwan, Samantha, 64-85. Oxford: Oxford University Press. 
de Beauvoir, Simone. 1952. The Second Sex. Translated by H. M. Parshley. New York: Vintage Books.

Bobel, Chris. 2006. "Our Revolution Has Style: Contemporary Menstrual Product Activists 'Doing Feminism' in the Third Wave." Sex Roles 54: 331-45.

- 2010. New Blood: Third Wave Feminism and the Politics of Menstruation. New Brunswick, NJ: Rutgers University Press.

Bordo, Susan R. 1989. "The Body and the Reproduction of Femininity: A Feminist Appropriation of Foucault." In Gender/Body/Knowledge: Feminist Reconstructions of Being and Knowing, edited by Susan Bordo and Jaggar, Allison, 13-33. New Brunswick: Rutgers University Press.

—. 1990. "Feminism, Postmodernism and Gender Skepticism." In Feminism/ Postmodernism, edited by L. Nicholson, 133-56. New York, NY: Routledge.

Bramwell, R. 2001. "Blood and Milk: Constructions of Female Bodily Fluids in Western Society." Women \& Health 34 (4): 85-96.

Brooks-Gunn, J., and D. N. Ruble. 1982. "The Development of Menstrual-Related Beliefs and Behaviors during Early Adolescence." Child Development 53 (6): $1567-77$.

Brumberg, Joan. 1998. The Body Project: An Intimate History of American Girls. New York: Random House Inc.

Buckley, Thomas, and Alma Gottlieb. 1988. Blood Magic: The Anthropology of Menstruation. Berkeley: University of California Press.

Chrisler, Joan (editor). 2004. From Menarche to Menopause: The Female Body in Feminist Therapy. New York: Routledge.

Cicurel, I. E. 2000. “The Rabbinate Versus Israeli (Jewish) Women: The Mikvah as a Contested Domain.” Nashim: A Journal of Jewish Women's Studies 3: 164-90.

Clarke, Adele E., Laura Mamo, Jennifer Fosket, Jennifer Fishman, and Janet K. Shim. 2010. Biomedicalization: Technoscience, Health, and Illness in the U.S. Durham: Duke University Press.

Conrad, Peter. 1992. "Medicalization and Social Control." Annual Review of Sociology 18: 209-32.

Delaney, J., M. J. Lupton, and E. Toth. 1988. The Curse: A Cultural History of Menstruation. Urbana: University of Illinois Press.

Ehrenreich, Barbara, and Deidre English. 2005. For Her Own Good: Two Centuries of the Experts Advice to Women. New York: Anchor Books.

Erchull, Mindy J. 2013. "Distancing Through Objectification? Depictions of Women's Bodies in Menstrual Product Advertisements." Sex Roles 68 (1-2): $32-40$.

Erchull, Mindy, Joan Chrisler, J. A. Gorman, and Ingrid Johnston-Robledo. 2002. "Education and Advertising: A Content Analysis of Commercially Produced Booklets about Menstruation." Journal of Early Adolescence 22: 455-74.

Fahs, Breanne. 2014. "'Freedom to' and 'Freedom from': A New Vision for Sex-Positive Politics." Sexualities 17 (3): 267-90.

- 2016. Out for Blood: Essays on Menstruation and Resistance. Albany: SUNY Press.

Forbes, Gordon, Leah E. Adams-Curtis, Kay B. White, and Katie M. Holmgren. 2003. 'The Role of Hostile and Benevolent Sexism in Women's and Men's Perceptions of the Menstruating Woman." Psychology of Women Quarterly 27 (1): 58-63.

Foucault, Michel. 1977. Discipline and Punish: The Birth of the Prison. Translated by Alan Sheridan. New York: Pantheon Books. 
1984. The Foucault Reader. Edited by Paul Rainbow. New York: Pantheon.

Fredrickson, B. L., and Tomi-Ann Roberts. 1997. "Objectification Theory: Toward Understanding Women's Lived Experiences and Mental Health Risks.” Psychology of Women Quarterly 21: 173-206.

Golub, Sharon. 1992. Periods: From Menarche to Menopause. Riverside, CA: Sage.

Grose, Rose G., and Shelly Grabe. 2014. "Sociocultural Attitudes Surrounding Menstruation and Alternative Menstrual Products: The Explanatory Role of Self-Objectification." Health Care for Women International 35: 677-94.

Guterman, Mark, Payal Mehta, and Margaret Gibbs. 2007. "Menstrual Taboos among Major Religions." The Internet Journal of World Health and Societal Politics $5(2): 1-7$.

Houppert, Karen. 1999. The Curse: Confronting the Last Unmentionable Taboo: Menstruation. New York: Farrar, Strauss, and Giroux.

Jackson, Theresa E., and Rachel J. Falmagne. 2013. "Women Wearing White: Discourses of Menstruation and the Experience of Menarche." Feminism of Psychology 23 (3): 379-98.

Johnston-Robledo, Ingrid, M. Ball, K. Lauta, and A. Zekoll, 2003. "To Bleed or Not to Bleed: Young Women's Attitudes toward Menstrual Suppression.” Women \& Health 38 (3): 59-75.

Johnston-Robledo, Ingrid, J. Voigt, K. Sheffield, and J. Wilcox-Constantine. 2007. "Reproductive Shame: Self-Objectification and Women's Attitudes toward Their Reproductive Functioning." Women \& Health 46 (1): 25-39.

Johnston-Robledo, Ingrid, and Joan Chrisler. 2013. "The Menstrual Mark: Menstruation as Social Stigma." Sex Roles 68: 9-18.

Jurgens, Janice J., and Bethel A. Powers. 1991. "An Exploratory Study of the Menstrual Euphemisms, Beliefs, and Taboos of Head Start Mothers." In Menstruation, Health, and Illness, edited by Diana L. Taylor and Nancy F. Woods. New York, NY: Hemisphere Publishing Corp.

Kaufert, Patricia, and Penny Gilbert. 1986. "Women, Menopause, and Medicalization." Culture, Medicine, and Psychiatry 10: 7-21.

Kissling, Elizabeth. 1996. “That Just a Basic Teen-Age Rule': Girls' Linguistic Strategies for Managing the Menstrual Communication Taboo." Journal of Applied Communication Research 24: 292-309.

- 2006. Capitalizing on the Curse: The Business of Menstruation. London: Lynne Rienner Publishers.

Lapekas, J. M. 2013. "Red Moon Rising: Breaking the Cycle of Menstrual Shaming through Countercultural Rhetoric." Retrieved from Proquest Dissertations Publishing

Laws, S. 1990. Issues of Blood: The Politics of Menstruation. London, UK: Macmillan.

Lee, Janet. 1994. "Menarche and the (Hetero)Sexualization of the Female Body." Gender and Society 8 (3): 343-62.

Lippman, Abby. 2004. "Women's Cycles for Sale: Neomedicalization and Women's Reproductive Health." Canadian Women's Health Network Magazine 6/7: 41.

Martin, Emily. 1992. "Medical Metaphors of Women's Bodies: Menstruation and Menopause." In The Woman in the Body by Emily Martin, 16-40. Boston: Beacon Press.

Patterson, Ashly. 2014. "The Social Construction and Resistance of Menstruation as a Public Spectacle." In Illuminating How Identities, Stereotypes and Inequalities Matter through Gender Studies, edited by Farris, D. Nicole, D'Lane R. Compton, and Mary Ann Davis, 91-108. New York: Springer. 
Persdotter, Josefin. 2020. "Towards a Definition of Menstronormativity." In The Palgrave Handbook of Critical Menstrual Studies (this volume).

Pickett, Brent L. 1996. "Foucault and the Politics of Resistance." Polity 28 (4): 445-66.

Pylpa, Jen. 1998. "Power and Body Practice: Applying the Work of Foucault to an Anthropology of the Body." Arizona Anthropologist 13: 21-36.

Roberts, Tomi-Ann. 2004. "Female Trouble: The Menstrual Self-Evaluation Scale and Women's Self-Objectification.” Psychology of Women Quarterly 28: 22-26.

- 2017. Personal communication, The Society for Menstrual Cycle Research, Kennesaw State University Atlanta GA, June 23, 2017.

Roberts, Tomi-Ann, Jamie Goldenberg, Cathleen Power, and Tom Pyszczynski. 2002. "'Feminine Protection': The Effects of Menstruation on Attitudes towards Women." Psychology of Women Quarterly 26: 131-39.

Roberts, Tomi-Ann, and Patricia L. Waters. 2004. "Self-Objectification and That 'Not So Fresh' Feeling': Feminist Therapeutic Interventions for Healthy Female Embodiment." Women \& Therapy 27 (3/4): 5-21.

Rozin, Paul, and April Fallon. 1987. "A Perspective on Disgust.” Psychological Review 94 (1): 23-41.

Ruzek, C. B. 1978. The Women's Health Movement: Feminist Alternative to Medical Control. New York: Praeger.

Stubbs, Margaret, and Daryl Costos. 2004. "Negative Attitudes toward Menstruation: Implications for Disconnection Within Girls and Between Women." Women \& Therapy 27 (3/4): 37-54.

Thomas. 2007. "Tips and Advice on Choosing a Pad." Accessed June 22, 2017. https://always.com/en-us/tips-and-advice/choosing-a-pad.

Thornton, Leslie-Jean. 2013. "Time of the Month" on Twitter: Taboo, Stereotype and Bonding in a No-Holds-Barred Public Arena." Sex Roles 68: 41-54.

Tiefer, Leonnore. 1995. Sex Is Not a Natural Act and Other Essays. New York: Routledge.

Ussher, Jane M. 1989. The Psychology of the Female Body. London: Routledge.

- 2006. Managing the Monstrous Feminine: Regulating the Reproductive Body. New York: Routledge.

-. 2017. "Unspeakable Womanhood: Experiences and Constructions of Menstruation in Migrant and Refugee Women." Paper presented at the Society for Menstrual Cycle Research, Kennesaw State University Atlanta GA, June 24, 2017.

Vostrel, Sharra. 2008. Under Wraps: A History of Menstrual Hygiene Technology. Maryland: Lexington Books.

Wood, Jill M., Patricia Barthalow Koch, and Phyllis Kernoff Mansfield. 2007. "Is My Period Normal? How College-Aged Women Determine the Normality or Abnormality of Their Menstrual Cycles." Women \& Health 46 (1): 41-56.

Young, Iris Marion. 1997. "Menstrual Meditations." In On Female Body Experience: Throwing Like a Girl and Other Essays by Iris Marion Young, 97-122. New York: Oxford University Press. 
Open Access This chapter is licensed under the terms of the Creative Commons Attribution 4.0 International License (http://creativecommons.org/licenses/ by $/ 4.0 /)$, which permits use, sharing, adaptation, distribution and reproduction in any medium or format, as long as you give appropriate credit to the original author(s) and the source, provide a link to the Creative Commons license and indicate if changes were made.

The images or other third party material in this chapter are included in the chapter's Creative Commons license, unless indicated otherwise in a credit line to the material. If material is not included in the chapter's Creative Commons license and your intended use is not permitted by statutory regulation or exceeds the permitted use, you will need to obtain permission directly from the copyright holder. 